\title{
Whither the Language Lab?
}

Abstract Language Labs have experienced many changes over the past several years, from changes in names to changes in direction. This edited transcription of a panel discussion at the 1994 TESOL conference by six experienced language lab directors provides an informal and free-wheeling discussion about the following questions: (1) What's in a name (change)? (2) What is the most appropriate role for technology with respect to language learning and teaching? (3) What is the role of the language lab vis-à-vis faculty and administration? (4) What are students' perceptions of language labs? (5) What has had the greatest impact on language labs over the last ten to twenty years? (6) What are the fundamental characteristics of the ideal lab director? (7) What is the greatest challenge facing the language lab today, as well as into the next decade? (8) Whither the language lab? What direction do we see ourselves moving in the next generation?

Moderator:

Trisha Dvorak, President of IALL, University of Michigan

Panel Members:

Brigitte Charlotteaux, George Washington University

Read Gilgen, University of Wisconsin

David Herren, Middlebury College

Chris Jones, Carnegie Mellon University

Ruth Trometer, MIT

Whither the [Editor's Note: The following is an edited transcription of a panel Language Lab? discussion presented by veteran IALL members at TESOL in March 1994. Although it is rather long (the panel was nearly two hours), $i t^{\prime} s$ worth reading. Editing changes have been made to make the text more concise and easier to read, but the basic content remains unchanged. Indeed, we have tried to retain as much as possible the spontaneous flavor of the panel. Because the panelists gathered before the session to "pre-discuss" the questions, some of the panel 
members sound as if they are continuing a discussion. In fact, the discussion continued long after the session was over at a reception hosted by Trisha Dvorak and later at Bertha's Mussels north of Baltimore.]

Introduction

Trish: The title of this session is "Whither the Language Lab?" Some schools have actually done away with language labs altogether. Others are expanding, remodeling, renovating, and adding new equipment, while other schools are trying to figure out if any of this matters anymore. What's happening to language labs around the country, and who cares? What role can they play in communicative language programs and in supporting faculty and curriculum development? Who are the next generation of language lab directors and what knowledge and skills must they bring to their task? What attitudes do students have about language labs and how does this affect their experiences as learners?

Many of you are language lab directors or are associated with language labs, so you share a lot of these same questions perhaps. We're going to explore these questions today in a panel. My name is Trish Dvorak and I'll be the moderator. I'm director of the Language Resource Center at the University of Michigan and also President of the International Association for Learning Labs. The members of the panel are themselves directors of language labs from different schools around the country. On my left is Read Gilgen, who is the director of Learning Support Services at the University of Wisconsin. On his left is Ruth Trometer, who is director of the Language Learning Resource Center-one of the labs that has changed its name recently-at MIT. On my right is Brigitte Charlotteaux, who is at the language lab at George Washington University. On her right is Chris Jones, who is at the Language Learning Resource Center at Carnegie Mellon, and on his right is David Herren, who actually has a much broader role with academic computing at Middlebury.

We're going to represent to you a variety of different contexts and settings but we have a lot of the same questions. The panel will actually look at about eight different questions:

- The first question has to do with the name. What do you call language labs anymore? A lot of language labs have changed their names from language laboratory, which used to be ubiquitous, to now something that is a combination or permutation of media center, resource center, even language acquisition center. So the question is why is this happening, and why is it happening now? What difference does it make? Is it trivial or is it significant in some way? 
- The second question is, "What is the most appropriate role for technology with respect to language learning and teaching?" I asked several members of the panel to talk about that.

- The third question is, "What is the role of the language lab with respect to language faculty and college and university administration?" That is, what is the perception of faculty and university administrators of language labs? Where do you fit in that context?

- The fourth question is, "What are students' perceptions of language labs?" What do they think about the language lab, and is that changing over time?

- The fifth question is, "What do the members of the panel think has had the single largest impact on labs over the last ten to twenty years and why do they think that?"

- The sixth question is, "What are the fundamental characteristics of the ideal lab director?"

- Seven, "What is the greatest challenge facing the language lab today, as well as into the next decade?"

- And the last question is, "where are we going, whither the language lab?" What direction do we see ourselves moving in the next generation?

Language Lab OK, we'll start again, then. Some language labs don't call Names themselves language labs anymore. We've seen a gradual, in some cases a fairly abrupt, change in the naming of language labs, and the question is if this is significant at all? Is it trivial? Why is it happening, and why is it happening now? So, I'm going to turn this over first to Read Gilgen from Wisconsin.

Read: I think in some ways this first question is the sum and essence of this whole panel. The whole idea of names in some ways reflects, I think, what is going on with labs generally and perhaps will serve as a kind of structure for where we go in the rest of our discussion. What we do, how we do it, our perceptions of our roles within the university and in language learning and all the other kinds of things, tend to get reflected in the names we use for organizations, so that may reflect a little bit about where we're going.

The first thing I was going to do was ask the panel at least what the specific name of their language learning facility is. They already did that anyway but I want you to listen for subtle differences. Trisha, yours is: "The Language Resource Center." Mine is "Learning Support Services." Ruth's is "Language Learning Resource Center." Chris' is "Language Lab of the Language Learning Resource Center" and Middlebury doesn't have a lab anymore. 
So we see some differences, and one of those subtle differences is "Language Learning Resource Center" and "Language Learning and Resource Center". Think about the subtle differences there. Anyway, we are fortunate that, back in the mid '70s and then again in the late '80s IALL (International Association for Learning Labs) conducted a survey of language lab directors to find out what was going on in their facilities. One comparison has to do with the name of the facility itself. In a twelve-year period there was about a $20 \%$ decrease in those that call themselves just "language labs." Now, that's not quite as significant as it may seem. The statistics also show that although the top item, "language lab," decreased by about $20 \%$, there was a great increase in language centers and other combined names that include the word "language." So actually there was only a relatively modest decrease. The word "language" is still staying in many of these names, even though they might not call themselves specifically "language lab."

My view is that these names change for a number of reasons. As I've looked at the kinds of transition of labs over the years, it appears that in the ' 60 s and ' 70 s, due to a number of reasons, language labs failed miserably in many respects. It may have been because they didn't have adequate budgets, a backlash from the audio-lingual method, whatever the case may be, there was a negative connotation that became associated with language labs in many instances. Not in all schools, and, in fact, in some schools they continued to thrive. But, in many places, they literally died. There was, indeed, a negative connotation that came to be associated with the name "language lab."

So, one of the reasons for name changes was the result of people wanting to distance themselves a bit from this term even though they knew they would still doing the same old thing. They just didn't want to be called a language lab. Other facilities sought to broaden their appeal and usefulness by serving other disciplines, and so the name changes were to reflect the inclusion of those new disciplines. You can see that the percentage where foreign language is the only thing taught or served in the language lab decreased pretty significantly between those years, but when you take a look at where it's mostly foreign language, it increased. I'm not sure what to make out of those statistics, but the labs did become more diverse in terms of the clientele they served.

Then, finally, partly in response to the idea of the negative connotation of the language lab and its dying on the vine, some of these facilities were actually gobbled up by other 
campus facilities, by media centers or whatever they may be. So, they may have taken on the name of the new media center or a new name was devised for the joint organization. I think the new names in themselves may not be terribly significant, but the reason for the change obviously is. An example is the instance where labs were gobbled up by other organizations. How much did the language learning pedagogy suffer as a result of that? I know that in my own experience I find that generally ed tech people don't really understand how ed tech applies to language learning. You get people out of the school of education, you hire them for your language lab and it's really an interesting experience. So, when you get an AV center that's primarily geared toward just AV instructional equipment, but it doesn't have the language focus, that can impact negatively on what you're doing.

Broadening your appeal-that was another strategy for many people-could also have either negative or positive effects. One negative effect, and we've seen this in our own organization, is that you can spread yourself out and then find that some of those new things you're doing are really interesting. As you focus on those, you kind of let language learning languish a bit. However, on the positive side, it does expose you to a variety of new technologies and new ways of looking at things-video, microcomputers and all that sort of thing - can revitalize what you're doing.

As you broaden your base of clients, a couple of really positive things happen, and I know that's the case in our situation. First of all, that allows you to get out of the control of a specific language department. In many cases you answer directly to a dean, which may not be better, but it's different. It's often better, I think, than answering directly to a specific department. Another interesting result in the IALL survey shows a dramatic drop in those who report directly to a language chairman and an increase in those who report directly to a dean or higher or to an AV center or a library or something like that. There's quite a trend there, and I think generally that's good. One of the reasons for that is that it gives you a little better claim to the budgetary resources. You broaden your base a little bit, you have dean-level support for what you do, you can fight your own budget battles, and then you have a little more control over what you can do. I think, generally, that's a good trend, but we can debate that as well.

Let me give just two examples of name changes. Personally, I went through some of the kind of thing we're really talking about. When I first became director of what was called 
"Labs for Recorded Instruction" at the time, I didn't like telling people I was a language lab director. I don't know why it was, but I was very uncomfortable with that and I would always say "The Media Center" or something like that, something they could understand. I'd say "Labs for Recorded Instruction" and they'd say, "Huh?" As we went on, we began to diversify, we began to spread out, doing things for more people. But I find myself now after 12 years in this particular job coming back a little bit more to my roots in terms of language, realizing that's really the bread and butter of what we do, and focusing on that. I feel really comfortable telling people now that I'm a language lab director, but I also add that we also do microcomputers and video and all the other kinds of things as well.

The other example is IALL's name itself. I wasn't involved in the name change, but it used to be The National Association for Language Lab Directors and... was it the '70s that we changed? I don't know whether that was the same kind of reaction again to a negative connotation to language labs or simply an attempt to bring in more people. It might have been a combination of both, but International Association for Learning Labs is still kind of generic and I'm not sure exactly if it really means what we do. The language component of what we do is, of course, what I think is critical, and we need to keep that in focus.

Trish: I think that one of the points that Ruth had was about the same question. As we expand to add services and to become more of a diverse place, there are some negatives as far as our perception by other people.

Ruth: The one comment that I wanted to add is that I always found "language lab" to be a unique descriptor. You usually have only one language lab at any given school, and you have one language lab director at any school, whereas you may have many media people. I know at the time when IALL's name changed, I was concerned about losing that definitive element. I think that, in fact, IALL as an organization has not diverged from being an association for language lab directors. I think it would be very odd if someone would come to an IALL meeting and do a science presentation on media. It would be very uncharacteristic. So, I think within the profession "language lab" is a unique descriptor, and, in fact, having done some research, doing ERIC searches, if you call up things like "media centers" or "learning centers," you can get a whole array of other people. A lot of libraries or high schools now call themselves "learning centers" or "resource centers" because they also are doing other things, and so, as a 
very unique descriptor, if you're trying to do research on strictly language labs, that is still the best term that you can use.

I certainly agree with Read that we do change our names for other reasons. But I'm very comfortable with "language lab directors" as a title because I think as language lab directors, our goal is of course to provide equipment, but we are also concerned about the pedagogy behind that. I think a lot of media people are not concerned about that. In almost any session that we hold, we talk about the pedagogy behind using the technology. You don't just throw technology out there. We're concerned about the design of our facilities, and how faculty will use them, if it's an appropriate use.

\section{The Role of Technology in Language Learning}

Trish: The second question has to do with the role of technology with respect to language teaching and language learning. Is there a most appropriate role for technology? Technology itself has certainly changed quite a bit over time; but the question is, has the role, the relationship of technology to language teaching changed very much, is it the same, is it different, and what direction is it going? So, I'm going to hand this back to Ruth and let her talk a little bit about that.

Ruth: As a very straightforward answer to that, I don't think the role of technology has changed. Technology is there to facilitate learning, whether it's in the classroom or whether it's in your language center, but there has to be again the pedagogy behind it, and that's what technology is for. I think what recently has happened is multimedia has opened up new avenues to people in that it permits new forms of teaching. Individualized instruction, where the student has many resources at hand, can be a very powerful tool that teachers can rely upon. It allows teachers to do things they haven't been able to do, for example, a lot of comparison work. I have a short video clip of some projects that we're developing at MIT. One example is a Shakespeare project where the professor shows many different video clips of a Shakespeare play. The student has access to original texts of the play, they can actually view different productions of that play, and they can clip out video segments that they want to watch or make notes on. It's a very powerful tool when you can give that kind of comparison mode to students. It allows them to see differences immediately. They're doing a lot of things with stage design and different directors' works. So, I think what has changed in technology recently is that the teaching or the learning environment has changed around that. 
Trish: I think Chris had some interesting comments on the same question that had to do with the unique contribution, things that technology can do that are difficult to do without it.

Chris: Among teachers, I find, and certainly this is my point of view, I ask technology to do things which I either can't do very well or don't want to do. When it's strictly things that I don't want to do, I think I probably don't do them very well with technology either. But what I really have in mind is an individualized instruction environment which, in a classroom, is virtually impossible for a teacher to supply. We're starting to learn how to do that relatively effectively since the arrival of computers. Audiotapes and videotapes were less effective in doing this. When you have the possibility of unlimited repetition, of error feedback, and so forth, and student control of pace, sequence and content, all of those things that are conceivable within a computer environment, I think that's something that you can do better with technology than you can in a classroom, and it supplements the work that is going on in the classroom.

The other thing is, of course, as Ruth noted, the arrival of multimedia. The impact in the classroom I think can be tremendous. Just the presence of video, for example. Now that's a very simple addition. Once you start combining it with the access and control possibilities of hypermedia setups, I think you really have a unique environment where students can have an experience, an "authentic" experience with foreign cultures which was really impossible previous to recent developments in technology. So, for me, technology has recently become very interesting in terms of language learning and I think it has a very strong role to play both in the classroom and the lab.

Trish: David's point of view approaches the question from a little different tack, particularly looking at technology in the classroom vs. technology in the lab. What belongs in the classroom and what belongs in the lab setting and what are some possibly inappropriate uses of technology?

David: I think that one of the things that has been driving technology is communicative methods that we have begun adopting recently. I think there has been a realization in the discipline of language teaching as a whole that what we really want to do is to teach our students to speak the language. I personally got involved in technology because I found that doing grammar in the classroom and doing verb paradigmatic drills in the classroom was an entirely inappropriate use of my classroom time. I was losing that time for real human com- 
munication. So my thrust, perhaps a bit radical, is I don't want any technology in my classroom beyond chalk. Technology should be relegated to-and I'm a nerd, a self-proclaimed nerd-I want the technology in the learning center, where I can send my students to do individualized instruction. I think Chris already covered that pretty well. Be prepared for the classroom experience and then come into the classroom for human communication in a communicative classroom.

I have to admit that I think, particularly recently, that some of the presentation technologies that are becoming available will be useful to us in the classroom. Again this has to do with reducing the amount of time spent on non-communicative activities. So, for example, we mentioned video in the classroom. I would rather not see videotape in the classroom at all because we all know you play the two minute segment of the videotape and then you spend a minute and a half rewinding it getting to the same spot so you can replay the videotape again. That's dead time, and it's taking away from the students' communicating with one another and with native speakers, so I'd like to see that taken out. I think with videodiscs and maybe some of the Kodak CD technologies we can begin to do things much quicker, use the media as a jumping off point for returning to human communication, which is what we're here for.

The Role of the Language Lab in the Institution
Trish: The next question really has to do with the relationship of the language lab to the faculty and administrative structure in particular institutional contexts. The language labs look very different now than they used to look. The design of the equipment, the technical specifications, all that has changed. But language lab qua language lab, what is the relationship of that institution or that unit to the faculty? What do faculty think about language labs, and what do university administrations think about language labs? Is it the same, or has it changed? I'll let Chris talk first.

Chris: Clearly in terms of faculty preparing materials for use in a language lab, if you think in terms of maybe 20 years ago, what would that amount to? It would amount to making a recording and using a mimeographed page to do a cloze exercise or something like that. Very few people would have done video. Now, they would, of course, and now many more people would do audio recording. And now you think about the possibility of faculty actually doing multimedia development. Now, to a certain extent, all of us are in the business of encouraging that. It's problematic. It's extremely problematic. We're here among friends, but I don't want to repeat that too 
often to my dean or even my chair because we're committed to getting as many people as possible involved in it as we can. There are still, I think, some primary misperceptions about what it means to do multimedia development. One of them is the old time thing and who can actually do it. What is the status of people who do it? What implications does it have for their promotion, tenure, and so forth? All those issues are becoming more and more obvious and especially for tenuretrack faculty. To get them involved with multimedia development when nothing but literary scholarship publication is going to get them tenure is definitely not doing them a favor.

Now, one more point. Our LLTI (Language Learning Technology International) discussion group is a list server which discusses issues like this. There was a discussion in which we talked about how efficient or not, in terms of cost, the new language labs or learning centers, resource centers, are or are not with computer equipment and laser disc players and CDROM drives and so forth. I think if we move strongly in this direction - and we have little choice at this point-then we're on an extremely high cost renovation track. Ruth and I were talking about this earlier: we're talking about a three-, or fouryear cycle where essentially everything we own is going to become obsolete or need updating. That's not to speak at all of the need for upgrading software, the need to repurchase commercial software, which will itself become incompatible with new hardware, and so forth. We're in a cycle which university administrators have accepted for their computing infrastructure. In other words, their computing services people have told them, "OK, you thought you bought it once. No, what we have to do is buy it once every three years." And that's for course registration, all that kind of stuff. Now, we're going to have to convince them that we are in exactly the same situation. As all of you who are language directors know, that's a problem. They're not there yet and whether they'll ever get there is another question.

Trish: Chris' perspective indicates that there have been some major changes actually in the relationship of language labs to faculty, particularly as language labs are beginning to be perceived as places to assist faculty in the development of new materials and the development of new curricula based on these new materials. Read had a different perspective, that things actually hadn't changed as much as we would have hoped in that language labs still aren't quite in a partnership relationship.

Read: I'm not sure that's what I said, but, the first part of that, yes. We are in a partnership. That part I think still holds. 
But I do believe that, from what I've seen, both at our facility and at those of other places, generally speaking, the role of the lab has not really changed all that much. I think there are two different aspects here. One where we have a responsibility to push and promote the technology, and the other where we have a responsibility to provide competently the technology that the faculty actually need. We're able to do this competently because we're able to share the costs, instead of one department buying a laser disc and another buying one and so forth. We can buy and house this expensive equipment, and the problems that Chris mentioned of having to recycle this equipment, at least it's going to the better good instead of individuals having to come up with these costs time after time. I think oftentimes the faculty view our partnership with them as falling into category A, pushing new technology, whereas I think sometimes we're just kind of nudging them. But we really have to be firmly planted in category B, where we competently provide them with what they need right now. We have a responsibility to help them see what's available but by the same token we've got to make sure that what they need right now is available as well. I think, for example, about our own situation. Many people from other institutions call me on the phone, and I can hear the expectant voice on the other end just wanting me to tell them about all these neat computer-assisted programs and everything that we're doing at the UW. I think that it's really hard for people to realize that a lot of places aren't like that. If we had to go around and buy computers and laser discs and all this multimedia stuff on multimedia stations for, what have we got, 2,000 language students or something just in the first year of courses alone, there's no way. We could not do it. It would be just simply impossible. So most of what we do is pretty much on a small scale and experimental basis. I like to say sometimes that we're the comfortable followers of technology rather than being on the bleeding edge, so to speak. We try to anticipate what faculty need. We're not always there. We try to find out what it is they need and kind of let them know what they will need along the way, and be ready for them, but we're not always successful. There's another question later where I get to comment on that. Sometimes we get blind-sided by things that come up, or sometimes we are indeed ahead of them. But we try to walk that tightrope of spending our resources wisely so that we buy what's going to actually get used.

Trish: Ruth wanted to say something a little bit different on this particular issue, and I think you can see here a real difference in contexts because Read is speaking from the perspec- 
tive of a very large university, the University of Wisconsin. I'm familiar with the kind of situation he is in because Michigan is similar to that, where we may have 2,000 students in the first semester of one course. Ruth, on the other hand, is from a smaller school, and her perspective is that the changes in technology and the roles of language labs play for faculty have opened up real new possibilities, when you have a bit smaller setting.

Ruth: Actually, changes at MIT started about ten years ago or more. MIT was given a very large grant for computing equipment and they had to go out and get matching grants to develop software around this. I think the administration was more than surprised that the single largest grant to come out of that was a project that was in foreign languages. They, of course, envisioned engineers and scientists and everybody else, but foreign languages was back there somewhere. Although we were off to a very slow start-it took us years to get our act together-that initial success of that one project has allowed the creation of a software development lab there. These projects certainly have excited faculty. In fact, now, faculty that are coming in are actually hired on the basis of what they know about media, using media, and if they're interested in it, if they seem comfortable with it. Almost every new person that comes on board will immediately come to the language lab and will know what I am talking about. They are familiar with computers, and they are using email already, which I think is a real shift for us. I mean, we still have a number of faculty that aren't up to speed, but, right now virtually all of our faculty use email. I think most of them are familiar with list servers, so there's been a real trickle-down effect within the department.

Right now we have four new projects that are coming out, and we're beta testing in the language center, which is a very new role for us. The provost comes over and sees all these new projects being tested, and we give the demonstrations in the language center. For the administration, all of this is a very different image of the language lab, which used to be in the basement with its twenty rows of audio decks. Just as an example, we gave a big demonstration of all our projects that were under development to our provost. During the discussion that followed, our dean actually said, "You know, Mark, this is really where the cutting edge of research is in the humanities now." For those of you who are familiar with linguistics at MIT, this is the dean at that department also. So, for us in foreign languages, that seemed like a real boost, that he in fact kind of considered this the cutting edge of research 
that was going on at MIT. This certainly helps us when we're trying to get funding from the administration. I think I see real changes in that respect. We're lucky in that we do have a department that can do all of the developmental work because it does require special programs, special video people, and people to go out and get grant money. That whole department's supported by grant money and we are really the delivery platform, so I think that's a real change and a hopeful sign from the administration.

David: I just had a brief comment that I wanted to add to that. As I'm growing older, I'm learning to be less flippant. I said Middlebury does not have a language lab, and that's true. We have about seven of them, so I should clarify that, although we never ever call them language labs. So the reason I'm telling you that is so you'll know why am I commenting on what is the role of the language lab.

I've been doing some work with the American Association of Community Colleges (AACC). I just came from the AACC conference sponsored by the $\mathrm{NEH}$ on language teaching in the community college and on improving that. One of the interesting things I found there is that community colleges are in a very unique position to really promote language and technology and here's a role I can see them play with respect to the faculty. That is, they can get faculty released time. We know that developing materials takes lots of time. Administrations largely think that if we buy some computers, we can increase class size and teaching loads because it will be easier to teach the languages. That's clearly and patently false. The faculty for years have gone to the administration and said, "Oh, God, we're so overworked, we need more time off." So the administration has turned a dull ear to that. I think that administrations need to have technologists coming to them and saying, "Here are services we have to offer, here is the money you have invested in this technology already, and it is going to go unused unless you provide some released time to faculty to develop materials." So I find that the language learning centers can play a unique role in getting the faculty the released time. That's something that you can push. Partnerships with faculty will get materials developed that won't get developed if it's only coming from the faculty side or only from the language laboratory side.

Read: One quick comment on that. You said "administrations." I think sometimes it's also legislatures. I think the public, versus the private, school also has some problems in this respect. For example, at the University of Wisconsin, the legislature was already screaming about the fact that faculty don't 
spend enough time in the classroom. To get released time at a large public institution is really difficult. I've got to think that at least in some private schools and I know in the community colleges and vocational technology schools, faculty have got a little more flexibility in that regard. But it's really tough for us.

David: Interesting, because community colleges are publicly funded, just as public universities. But that's why I find that the community colleges in particular are in a position to push for that.

Audience Question: I'm sure your board of trustees at a community college are not unlike your legislature.

David: Interestingly enough at this conference that I've just come from, there were several projects involving technology, and one of the unique aspects of this particular conference was that the NEH required two faculty members and one administrator from every school to attend the conference and forced the administrators to go to every single session and sit in with their faculty. They came away from that saying "OK, released time." So, at least if you can get the administrators on your side by exposing them to the advantages there, then you have a much better chance of getting some yielding from the trustees.

Student Trish: The next question is one about which you all probPerceptions of Language Labs ably have, I want to say opinions, maybe more visceral reactions. Many of you remember being a student studying a language in a language lab. I went, I think, once for one 20minute session. I don't think I ever went back as a language student. Have student perceptions changed? We've been talking about lots of changes going on in language labs. What do students think about language labs? Have their perceptions and their opinions about what these places are changed over time?

David: I'm the primary respondent, and you've all been waiting for hard data on how language learning centers affect students. I don't have any. Correct me if I am wrong. Everything you're going to hear is going to be anecdotal. I don't really think there are any data out there. We're trying to find ways to gather it. At Middlebury at least, we did have a language lab. We had some rows of cassette desks all facing in the same direction with heavy headsets and students went like this and everyone was touting, "We can pair." Well, I've always thought, take the damn headsets off, put them in a corner and let them pair, and that was a little bit more effective. As we've introduced hypermedia technology into the 
learning centers, well, we've just dismantled ours (language labs). About a week ago we completely tore the last one down. No one ever used it except for about two hours a week in the summer; it wasn't used other than that at all, it just was a room sitting there, and we needed the space more. But as we've introduced more of this technology into the learning centers, the students' opinions are that it's way cool, and they like to come down there. We have materials available for them, of course, language materials, but we also put in a lot of other way cool things to entice them to come. We find that they go out surfing the World Wide Web and they come back and find language materials for us-just by letting them surf. I think it works for the students. They come in droves. We can cite many, many anecdotal examples, and I can cite some from Vanderbilt and some from Butler University and some other places that I'm associated with. But beyond anecdotes, I don't think we have data.

Trish: And, Ruth, I think you were going to talk a little bit about this, too, in terms of resources.

Ruth: Well, I think David is right, that the new technology certainly entices students into the lab and they are more entertained. I have never heard of a student who doesn't like an interactive video program. It seems to challenge them. What I also see, though, is that the old technologies aren't dying out. We still have some students that want to come in and use an audiotape deck. New learning centers seem to offer a large variety of tools. At some point a student might move beyond an audiotape and start using a videotape. But I think that offering a whole variety of resources for students should be a major function for a language center because you can tap into people at different times and at different levels. Some people love to watch videotapes, whether it's an instructional videotape or a movie or whatever. Then again, there are a lot of people that just want to go through grammar drills on a computer. So I think that offering a variety of resources is very important. And having this wide variety does encourage many more people to come in and use your resource center. Ours is full most of the time.

Read: We have found, again this is anecdotal, sort of, but it's also statistically borne out, that the students' perceptions of the labs do make a difference as to how much the students use the labs. There is a correlation there that we have found, and I've done it from an instructor's point of view as well as from a lab director's point of view. The first question to be asked is, "Is the lab required?" The instructor says you must study in the lab one hour per week. That's one part of that. 
Then you get into the other questions: If it is required, what do they actually have to do? Do they have to go and drill there with an instructor, or do they go and drill in a library mode? Do they go and check out a tape and take it home? Are they required to spend a certain amount of time in the lab? Some classes require them to punch a time clock, and so one student comes with a sheaf of time slips and punches them all, comes back a half hour later and punches them all and passes them back to all the students in the class. Basically, we have found that if students feel that what they are being asked to do in the lab is really benefiting them-in many cases that may simply be "it's going to be on the test, so it will benefit you" - they will use it. It's really interesting, you can tell what kinds of assignments are being made by the way the lab is being used by those classes. A particular course will come heavy duty at the beginning of the semester, and already, by the fourteenth week of the semester, they're still coming in pretty big numbers, whereas in another one they come heavy duty the first week and after the first week, boom, it just drops off. You can tell just exactly what kinds of requirements are being made for the lab.

I'll never forget a Spanish quiz I gave one time. It was a dictation exercise. I got through giving this exercise and the students, a couple of them said, "Boy, you know, it was really hard. Where'd you get that? I've never seen that before." It was directly out of the lab workbook. I said, "Well, there it is. Go to the lab. I want you to work on this material."

Whether or not it's required, we have an obligation to make sure that the quality of what they get is indeed what they expect. We've always prided ourselves on having good materials. This last semester we had a situation come up where, suddenly, we just got a raft of complaints about the tapes and the quality and all the problems that were going on. We just thought, oh, no, they're grumbling again. But it really got out of hand, so I went in and I grabbed a tray of tapes for French 101 lesson 13, or something, and I sat down and went through each one of those tapes. Out of those 20 tapes, three of them were French. The rest were Italian, Russian, and German. Basically I had a quality control problem. We changed the person who was doing the tape duplicating and the problems went away, but, nevertheless, already some of the damage had been done. So quality control of what they have is really extremely important. It's just like a library. If they go in and ask for a book in the library and they get the wrong book, they're going to stop going to the library after a while, and it's the same thing here. 
So, it's got to be good quality, they've got to want to go there, and they've got to view it as a resource center. I think the student's perception has changed from viewing the lab as a place where they go and they do things to viewing it as a resource. They may go there and do things, but it's where they can get help for what they're doing more than a physical location where they have to go and drill.

Audience Question: Ruth, may I suggest that the reason they come there to do audiotapes is because they only have CDs at home now?

Ruth: Well, we're going to have to put that question out on the network!

Impacts on Language Labs

Trish: I was curious to find out from the panel what they thought had the single biggest impact on language labs over the past couple of decades. So, Brigitte, what do you think?

Brigitte: As far as I'm concerned, in my university, it's definitely the video because suddenly teachers who were not very interested in using the lab came to the lab to use "MiniScholar" from the third year to the fourth year. But from that some of the teachers became interested and started to use video, movies and different things and were able to cut different parts to use for the classes. Besides video, I think there is an impact from computers, too. We don't use computers as much because right now we don't have enough. We don't have a computer lab. So we use computers only as a pilot program. But definitely the video is the most important part in our university.

Trish: David, what do you think?

David: I had misread the question, I must confess. So, uncharacteristically, this is off the cuff. Clearly, I think the single largest impact upon the laboratory has been the computer, but not for the sake of computing. I think that sitting and doing exercises that are solely computer-based, where the computer isn't just a remote control to media, I don't see too many advantages to just simply using the computer that way. Just simply as a remote control and remote access to information,that is advantageous. Video is there; you know it's hard to think about the fact that video has not really been with us twenty years. So to say what's been the single largest, I'd have to go with Brigitte and say, well, really, video, but, now that we can control the video and add to that video and we have more instant access to video, I think, I guess moving images would be the biggest advantage.

Audience Question: I would like to clarify that, if possible, about the computer as a remote control. I didn't quite understand that. 
David: In other words, a computer is really just a tool, just as chalk is a tool, so we don't have conferences to talk about chalk. John Bear, an old friend of mine, who wrote a book called The Computer Wimp really summarized this best. He said the computer will never be an effective tool as long as we have computer users' groups. He said you don't find vacuum cleaner users' groups out there, so he called it the Hoover Users' Group. So I guess I'm just trying to de-emphasize the computer part of it, which is that piece which terrifies faculty. It terrifies increasingly fewer students every semester but still often terrifies faculty. So I see the computer as being a remote control to drive your video disk, to drive your audio disk, to drive your photo CDs, bringing in authentic materials; and it's just a way to connect those disparate media and present them in more or less a unified presentation to the student.

Trish: There's been something else that has had a major impact on language labs and actually on language teaching that a lot of us don't think about except when we run into it and run afoul of it, which is happening a lot more frequently now as there is more and more development going on.

Read: In the 13 years that I've been director at UW, probably the legal issues have been one of the greatest impacts on my life as a lab director, for good or for bad, mostly I think for bad. Not really, it's necessary and all the rest of it, but I've been more consumed by this than I would have ever thought thirteen years ago. Copyright, for example. When I first started, copyright meant that instead of taking the taped music segments that we had and putting them in our collection, we had a little hidden card file that we kept in the drawer of one of the librarians so that it wouldn't be illegal. It was no big deal. Now copyright just pervades everything that we do. I think, for example that we've got several missions when it comes to copyright. One of them is to understand and implement the copyright law properly, and not necessarily believe everything we hear out there, but find out what copyright restrictions we do have. We need to set the standard for copyright compliance and to educate faculty, and make them do it, force them to do it. When they come to us with $L a$ Belle et La Bête and they want us to make a copy to put into the lab, we say no, and we stick to our guns when it comes to copyright infringement. But we also have a role as lab directors, and we've tried to do this at UW, to push those limits a little bit, not so much that we get into lawsuits, but when we purchase things, for example, to put on the purchase order "We will be making copies of this for use in our language labs" and send it through. If it comes back, then we go ahead 
and make copies. If they balk at it, then we won't buy the tapes. With audio materials we've always done that. We've rarely had problems with that. With video materials we've had problems with it all the time. We have to deal with distributors, not copyright owners, and they're not quite so liberal with it. But we think we have that responsibility as lab directors to try to mellow out a little bit the copyright hysteria that's out there. A lot of it is not black and white but gray, and it has not been tested and it's not law as much as it is interpretation by people who make a lot of money giving seminars on copyright law. But we do need to understand what the law is and abide by it.

A couple of other legal issues. Personnel issues are a major thing. I spent the better part of an entire year going through personnel commission proceedings and hearings and depositions I had to give and the whole bit to prove that the person that I had let go, I let go legally. I didn't think I would ever do that again. I did it again about three years later. I was really good at it by this point. But making sure that I understand personnel issues and legal issues that relate to personnel issues, so that when I have to do something that is for the better good of the lab, then I can do it. We have to be careful with that.

The latest legal issue is the ADA (Americans with Disabilities Act). We need to find out what we can about it and be ready to implement it and do our best to accommodate people who have special needs to make sure that we're complying with that law. So, those are some of the challenges that I've run across. Again, increasingly, a large percentage of my time is being spent dealing with legal issues as opposed to just worrying about the latest in technology and how it applies to language learning.

\section{The Qualities/ Qualifications of the Ideal Lab Director}

Trish: We want to have audience participation with this next question. We'll have an audience fill-in, although we don't have any pens, unfortunately. Given all these changes in technology, changes in the role of language labs with respect to faculty and administration, how we' re affecting differentially students' lives, all of these various questions, we were interested to find out what the panel thought about what kind of people do we need in the role of language lab director? What are the characteristics that are the most important? So, I posed about seven different qualities and asked the panel to rank them from one to seven, with one being the most important. So, take just a minute and see what order you come up with: 
- Organizational management skills

- Technical expertise

- Instructional design expertise

- Experience and expertise in language teaching

- Commitment to service

- Commitment to research and development

- Knowledge of another language or experience with another culture

So, if you had to rank order those in terms of the person that you want in your language lab's director, what are the most important qualities?

You'll find it interesting to learn what the panel came up with:

1. Experience and expertise in language teaching

2. Organizational management skills

3. Knowledge of another language or experience with another culture

4. Technical expertise

5. Instructional design expertise

6. Commitment to research and development

7. Commitment to service

Now, we were not unanimous; there was no single item that actually got all six panelists all saying the same thing. But, on the other hand, there were a number of them that had fairly strong agreement. I think this is somewhat different from what might have been a couple of years ago in terms of what the qualities are. Brigitte Charlotteaux will now tell you a little bit about what her perspective is. Brigitte, in addition to being a faculty member at George Washington University is also head of the regional language learning lab association. Her association did a survey of the language lab directors, and she can report on what that regional group came up with in terms of the qualities that were most important.

Brigitte: I myself use video very frequently and it's one of the tools I use. However, I don't use it in the classroom, but I use it. I send the students to the language lab to work on video. I help a lot of teachers who change their courses, and I have some impact in having the department change the curriculum. I don't think I could have done that if I had not been a teacher, if I had been only a language lab director. And vice versa, if I had not been working in a lab, I don't think I would have known, really, how to use the equipment, to make it easy for the faculty to take it to the classroom if they choose to. So, that's why "experience and expertise in language teaching" was my first choice. Also, when we did the survey of a lot of language lab directors in our region, in the Mid-Atlantic 
Language Lab Association, many language lab directors indicated that if they were not directly part of the faculty, they would choose if they could to teach courses in whatever was their language. And most of those places which had the benefit of someone who was wearing two hats, they seemed to be much more active than some other places, at least at the places I have seen. Now, the second part, I think it's very important to be familiar with very different cultures. In our schools, we have a very strong East Asian department, for example, and also another department, the Slavic department. Most of those people are native to the language they are teaching, and they have quite a different way of relating. However, when you have a teacher who is asking in their own way for something, but doesn't really transmit the message as we would expect her to transmit it, then sometimes we don't respond correctly and she sees the language lab as being a place that's not helping her. If you are used to their culture, when they ask you in quite a different way, you can anticipate exactly what they need and help them. So, I think it's another component of, an added dimension of a language lab director. They should be really familiar with the foreign culture. Also, if, in your university, you have EFL students, well, that's the same thing. You have to be very careful in staffing your language lab with students who are quite ready to deal with people who are not able to communicate in the language because they are learning it. So, they have to be quite ready to anticipate their demands and help them, and maybe sit with them for some time, in some cases.

The technical part is important; however, I think it's even more important for the language lab director to be able to get the right staff that know how to do it, because otherwise you can be a jack of all trades and master of none. It's much better to have all of the management skills necessary and teaching skills and find an adequate person who is really going to be able to help you. Especially in the case of computers, for example. The extent of the support you can give for even software, if you don't have the right person to help you, it can be quite disastrous. Someone wants to use it and you do not want to help them. So, one of the ways that we solve the problem, because I have a good engineering school, is that I go directly to the engineering school and get some of the students who are in computer science.

Instructional design, I think, is extremely important also. For example, you can help faculty prepare for a conference. You can help them to produce a good video, and put slides in a video, and it really pays off. That's another thing I've found 
out, you help the teachers, and they come back to the lab and they bring their students. Suddenly the language center becomes a little bit more important.

Of course, organization and personnel management skills are very important to keep track of everything. For example, if the teachers are sending the students to the lab, we have to somehow report to them what the students are doing. I use the lab for that. But we also need to be very organized in managing our staffs. One of the things that most of us in the language lab are dealing with is budget restraints. We may not have all the personnel we need, and we have to use so many different bodies to fill out the hours.

And then, the sixth one, commitment to research. This one I don't feel as strongly about, however, if it is keeping statistics, it's important.

Trish: I think Read has some additional data.

Read: Some interesting things from the IALL 1988 survey again: the type of persons that were lab directors in 1976 versus 1988. First of all, we saw a huge jump from $23 \% \mathrm{PhDs}$ in '76 up to $44 \%$ in ' 88 . There's been a huge drop in ABDs, a slight increase in masters and slight decrease in BA and post BA. So, basically, the educational level of language lab directors has increased fairly substantially over that 12-year period, at least. I would suspect, actually, that that's a trend. I don't know about the rest of you, what do you think about that?

Audience Question: Do we have a chart which compares the rate with which departments are tenuring up in different language labs?

Read: We've got some other things here. Probably going along here with PhDs. More PhDs also means more females, right? We've had a narrowing of the gap, with quite an increase in female directors from $21 \%$ in 1976 and $43 \%$ in 1988. In the chart showing appointment types, we see a decrease in the faculty appointment types, and a huge increase in administrative types - faculty support, or associate faculty, or whatever you want to call them. They call them academic staff at the University of Wisconsin. But rather than having a tenured base in a tenure-giving department, they work from a different angle. We've seen a lot more of that in the last several years.

I've noticed, myself, a greater professionalism generally among lab directors, and I think it's also been shown in the revitalization of IALL, for example. It kind of floated along for a good deal of time there in the '70s and early ' 80 s. Toward the late ' 80 s the national conference, thanks to Ruth, 
finally got off the ground again and we've gotten going with that. We've had, every two years, an international conference. We've participated with the Japanese Language Lab Association a couple of years ago in Japan and had about 50 people from IALL that were there. So it shows this real increase in professional activities. The IALL Journal has established itself again as a real voice; the Language Learning Technology International (LLTI) list server on the Internet has been going very strongly. How many of you, by the way, have plugged into that at some point? If you haven't heard about that and are really interested in communicating and sharing ideas or just eavesdropping on what other lab directors have to say about their profession, you really ought to know about LLTI. It's really a fabulous resource.

We are lone people on our campuses. There is nobody on our campuses like us. So, unless we network with other people through our profession, we really don't have anyone to talk to. We've got regional meetings now going, most regional organizations. You can travel to these meetings. It's not a real hardship. And you can network through the computer list server. These kinds of things really help you say, "Yeah, I'm on the right track. Courage. Move forward." The professional aspect of our jobs has increased dramatically over the past several years.

Trish: Were there any other points that any of the others on the panel would like to make?

Chris: My reaction, to a certain extent, to the division of this position into all these skills was that, of course, they vary widely from one institution to the next. Think of, for example, Read or Trish's responsibilities, or even yours as compared to mine, they're radically different, starting from an institutional perspective. In other words, if you really have thousands upon thousands of students in basic language courses, then you can't afford to have a language lab director who does research and development. You have to have an administrator who has the administration and management well in hand before anything else happens. I'm at Carnegie Mellon University. Research drives that place, so that if I do nothing but manage and don't innovate, I don't fit the culture. So, it really depends very much on what the institutional environment is and what is expected of both staff and faculty. I think that changes pretty much from one institution to another.

Read: One thing I'd like to add to what I said about our being alone on our campuses. Stop and think about what makes a language lab director unique, and over the years I've come to believe it's three things. One, it's the technology and 
technical expertise, whether it's expertise or knowledge enough that you can talk intelligently enough about it. Two, language learning and language teaching background. You've got to have been in the classroom and know what it's like to teach language. Three, the administrative side of things. It's very rare to find that combination of things in one single person. That's why it's very difficult when you're out there recruiting for language lab directors. It's very hard to find people with these kinds of qualifications.

\section{Challenges Facing Language Labs}

Trish: The next question has to do with what are the greatest challenges facing language labs, not only in the current environment, but anticipating a little bit in the next generation or decade. What's the challenge that's facing us? Chris?

Chris: I think the greatest challenge facing language labs is the fact that all the need for machines is breaking down. What we're going to end up with, and it's become a truism, all we're going to have is data, and this data is going to be everywhere and nowhere. In other words, we may be using data that is no longer present in our language lab in any form that's recognizable. Now, that may seem a little obscure. What I'm talking about is having media resources which are remotely accessed. We talked about that a little bit in the sense of the World Wide Web. Video that's stored centrally in Washington, audio that's stored in a remote location which you access in that way, and so forth. Language labs are going to be caught up in this information feeding frenzy, which is going to be a national concern, and it has very serious implications for continuing our way of life, as it were, because we've been sort of defined by surrounding ourselves with technology that is becoming less and less comfortable. In other words, the audio machines were comfortable. You could pretty much handle them, they weren't that bad. VCRs are comfortable, we all have them at home. Computers with peripherals, laser disc players and CD-ROMs are still pretty much comfortable. We control them, control access to them, loan them, use them in the lab and so forth. Turn them off. When the information is out there and can be accessed just as well from the students' dorm room as it can be from a computer station in our lab, why are we [lab directors] there? What is the definition of our function? It's going to be redefined. That's sort of a radical, revolutionary concept of what's going to happen. Of course, this is going to take probably decades. It may not, however. It may take five years, it may take three years. There are developments going on that affect what we do in an extremely radical sense. So, that's the greatest challenge, from my point of view. 
Trish: Actually, you had said something else earlier. I wonder if you remembered this, that earlier on you were saying you thought technology was not going to be the challenge. The challenge was getting people to use the technology.

Chris: I did say that, didn't I? I'd better say that, too, then. It's kind of a less tantalizing idea because it has to do with practice rather than prospects. For example, at Carnegie Mellon, which is allegedly a computer intensive environment, there are people who use, for example in the classroom, use extremely sophisticated presentation devices, all the peripherals, laser discs integrated into a class presentation, including outlines, animated outlines, bulletins, and so forth. Well, I don't think that's all that useful. I'm still trying to get my faculty to even understand what a laser disc is and even use a bar code, something like that. Then, maybe do electronic correction of documents. There are little things which are very basic which faculty are still not doing: using text-only exercises in the lab, for example, and not using authoring systems which are now commonly available.

To a certain extent, we have a lot of really useful tools which are not in use. So, we've got the tools. Now we've got to get people using them. That is a much more down to earth appreciation of what our challenge is. Of course, the challenge, even if the tools change, the challenge will remain the same if we can't get people to use them until they're useless. No matter how groovy they may be, there are many language teachers who are fundamentally unimpressed unless they can see a clear and very direct way of using it themselves.

Ruth: Chris' statement about networking, whether it be decades away or five years away isn't all that wild and woolly. Our current department head is a Japanese instructor, and he's talking about the virtual language lab and he wants it to exist within MIT for the Japan program within the next couple years. They pulled down a big resource from the Internet, a grammar package and a dictionary. They have built an entire course, quizzes and all of the print documents. All of their texts are now handled through the MIT network. The students access it through their dorm rooms, they don't ever come to the language lab, and we've just recently been having meetings to put all their audio on the same basis so that the students don't have to go to special Sun work stations, but they can go to any work cluster around. It's really not all that far away as networks improve, as compression schemes improve or get standardized, it really is a possibility. I see it happening very quickly, actually. 
Read: We've kind of come that way, too. This whole idea, we had a big discussion on LLTI a few months back on the virtual lab, and, to some lab directors, it's a little bit scary. But when you stop to think about it, it really is what we've kind of been doing already, at least in our facility. It used to be they had to come and sit down and listen to a professor and listen to tapes. Then they came on their own and listened to tapes. Now they come and check out a tape and take it home. So, we end up being providers of whatever information or materials, whatever it is they need. We just built ourselves a gopher server about a month or so ago and all of our listings, all of our video collection, all the rest of it now is on the gopher, and so anybody, in fact any of you that have gopher can plug in and find out what we have in our collection (and, no, we don't lend things on interlibrary loan!) Anyway, the students are finding out about things we have and already we've got students coming in and asking about things they never knew we had. They could have looked it up in our catalog, but they never did. But the gopher's becoming a tool. They don't think about the computer. They think about information. It's like the telephone. They don't think about the telephone. They think about talking on it, and that's what they're doing with computer access now.

So, our next step, then, is working on a proposal where one of my people says "Why don't we just do this? Make audio materials available through the Internet. I mean people just dial up and they get sound." Of course, there are a few copyright problems here. But this whole idea, this whole concept of us becoming the providers of materials and information and so forth as opposed to the caretakers of a facility. I think I mentioned that before. We're a resource rather than a place, and I think that's the trend we're going to see here.

Chris: Some interesting statistics with respect to reinventing the lab and it (the lab) actually being in student rooms. Last year alone, Apple Computer sold one million CD-ROM drives in this country, and those are stand alone CD-ROM drives. That doesn't count the ones that came in every device, and they've announced that in this coming year they won't sell a computer that doesn't have a CD-ROM drive in it. So, when we look at that and at the information that can be disseminated that way, plus all their machines are now coming with ethernet on the motherboard, not having to drop in extra cards or anything like that. We're putting a lot of power out in student hands for very, very little money relatively speaking and I think we're going to have to reinvent ourselves as lab directors and be providers of information. 
Read: One more comment on that. I've always felt that the technology that we're involved with becomes reality when it gets to the consumer level. It happened with the cassette tape, it happened with video. In 1986, when we remodeled our labs, we asked all the faculty what they needed and they said, "We need a dial access system" which is what we had already. So, we basically geared up for audio. But two years later we got blind-sided by video because that's about the time VCRs made their way into everybody's home. People were coming with tapes and they needed to use video. Look around you at the kinds of things that are becoming consumer level accessible, like you said, the CD-ROM and all the rest of it. Your comment was good about how they come to the lab to use audiotapes because they don't have audiotape players. All they have is CD players at home. What is it that's consumer level? That's the technology that we'll be involved in.

Whither the Trish: Our last question, actually, I'm now wondering if we Language Lab? need to deal with it separately. You may already have a sense of how the panelists would answer "Whither the language lab?" Where are we going? What I did in this particular case was to give each panelist some options to answer that question. Are we full speed ahead, the greatest challenges are still ahead of us, do we have a lot of changing still to go? Is it that we actually already covered the greatest distance and our challenges are behind us and what we need to do is consolidate and get clear on that? Are people somewhat concerned about their future because of budgetary crises and that the technology is there but nobody has any more money to buy any of it? That's a real problem for a lot of us. So I really wanted to know what people thought. I'm still hoping we're going to finish in time for you to ask questions. I'm going to ask members of the panel to be very brief on this one.

David: Middlebury's already dismantled its language lab. The language lab has withered. Long live the lab director. This is my opinion, obviously. We cannot afford language labs anymore. We have to get rid of them. We have to have cooperative learning centers with other departments. Very few budgets can afford having a single purpose facility. I think we need to just get rid of them altogether and have multipurpose facilities because what is the goal of teaching language? You want the student to speak the language and you want them to have an appreciation of culture. Until we can bring in historians and get them involved in the process, and until we can bring in sociologists and until we can bring in other members of the humanities into the process of language teaching, 
we're not going to achieve our goals. If we have a center that says language something or other it alienates the faculty that we so desperately need in the process.

Brigitte: Well, I'm not really sure what I want to say after that. Now I feel somewhat taken aback. I'm not so sure anymore. However, I agree with you in the sense that in order for us to be known by the university, not just be considered as a language center, we have done a lot with sociology, with the art department, with anthropology. For budget reasons, but it comes to the same thing. I know otherwise we would not survive. So we do a lot of work for other departments. And we invite them to use our labs.

Ruth: Well, I of course think full speed ahead. I think money is going to be a real problem. I think until we can get labs to be on a cycle or become a larger type of facility.... There's already talk at MIT of building a humanities learning center because we do now need it. I was talking about the Shakespeare project, there's a writing project, there are a number of disciplines that, now that multimedia projects are available, they are very interested, whereas of course with audio and video they weren't that interested. But I do think money is going to be a concern for a while. The administration is going to have to go through some changes. I really see the networking as the future, that basically the facilities will become more production areas and they will be distribution places. Testing of materials might go on because you still have to have people come in and use them and test them. Do they work right? That's basically the way I see it going.

Read: We were talking earlier that the three buzzwords these days are network, multimedia and distance learning. I think certainly those are things we're going to have to watch, but I think basically what it really boils down to is we have to have one foot firmly planted in reality today and always be looking forward to where we're headed, and try to balance that fine line between promoting the new technologies, the new methods, the new virtual labs, whatever the case may be, and meeting the needs currently where people are at. We have to be a kind of change agent but we also have to kind of be a service agent as well. That's a really fine line that we have to balance. I'll go back on Monday and I'll still be providing audiotapes to French 101 students. I mean that's the reality of the situation.

Chris: I find myself in the situation where, in fact, as a virtual language laboratory, it's pretty much in existence because I have a small, incredibly intensive facility, which is just about big enough, once we get rolling, to work as a faculty 
development lab. It is now the full service lab and once it gets rolling, it will just be buried, and there's no more money. At that point, we will start exporting things on a server. We'll start using the network intensively, we'll start loaning more things and, little by little, the only thing we'll be doing is the heavy multimedia stuff, which means a laserdisc or CD-ROM disc which has been produced and so forth. That will be it. The multimedia will be all. Everything else will be decentralized just by absolute necessity. Now, I also think that corresponds to directions in terms of what students are going to have to work with in a larger societal directions.

\section{Audience Questions}

Trish: So, what do you think? Are there any questions from the audience? Do you want to ask the experts?

Audience Question: First I'd like to thank you for bringing your collective expertise here. I've worked at three large state universities and, in each one, the role between ESL and language labs has been different. One ESL department felt they got no support at all and decided they had to go it alone and, because most ESL departments at universities are self-supporting, this particular one could afford to do so. The other two have been a combination of some sort of collaborative effort and for some reason, ESL being very interested in computers and dominating the computer side and foreign language keeping a pretty firm hold on the listening/video side. What do you see as you look down the next five years? Are we going to be part of that sharing that you're talking about in the humanities or do you see, are you frightened by the ESL side?

Brigitte: I think ESL-I keep calling it ESL and EFL-is the bread and the butter of the universities. Therefore I think it's very good for the language lab to support EFL and when I took over the lab, most of the changes I did were all around EFL needs because, in return, they are the ones who supported me the most. I think it's in the interest very much of the university itself, but also of the language lab to support EFL.

Read: I would agree there. We work very closely. ESL is for us the same as a foreign language and they work with us, we work with them the same as we work with any language department, and in fact we have a very good relationship.

$R u t h$ : I don't know if this answers the question, but a really interesting aside is English students don't in any way support our programs because we don't have a summer school, and they have to have already passed the TOEFL test to get into MIT. There are special remedial classes and they are certainly integrated in as far as use of the language center. One 
thing I find interesting and it has to do with the foreign students in general, we really try to encourage them to come into the lab. We set up a lounge where they can watch the foreign language news broadcast, and that has on occasion set up some really interesting dialogs between the people that are studying the language and the native speakers there. Again, this doesn't really address the ESL question, but personally I think considering all kinds of communities that are in your school will always benefit your facility.

David: One of the buzzwords at the AACC conference that I just came from was articulation, and they were talking about vertical articulation and horizontal articulation. I didn't know what that meant before I asked. Horizontal articulation is relevant here as you see fewer and fewer places calling it a foreign language facility or talking about being a foreign language teacher. You talk about language teachers, and EFL people are language teachers just as everyone else. But I think we need to get the horizontal articulation going there between EFL students and other language students and vice versa and that if we start pairing our students this way, we can all benefit. So, I don't feel threatened at all by the EFL people and would like to see them more involved in the language teaching process, formerly called foreign language teaching. I think we who have been formerly involved in foreign languages have something to offer the EFL people in terms of pairing our students with theirs.

Audience Question: I feel like I'm one of the faculty members who's trying to run to catch up with you folks. I come from a community college in Massachusetts. I believe there's a grant that we have to equip a new lab, but it sounds like if we equip this new lab and spend all this money, it's going to be obsolete in three years, by the time the faculty figures out how to use it. I just bought in my home a new Mac computer and now I hear that the next generation is all going to have CD-ROMs and mine doesn't. I might as well throw it away.

David: No. First, you can attach a CD-ROM to just about any computer, so don't worry about that. I have three postulates of computing and the second one is relevant to this. That is, if you can buy it, it is already obsolete, so you have to get over that, that's all there is to it. So, the obsolescence issue, we can't deal with that. The technological advances are coming very, very quickly. One of the real issues is underutilization. We just got a grant, we just bought a lab and we trotted the trustees through to look at the lab but now six months, a year later it's really underutilized because the faculty don't know how to do it. I think that, to a certain degree, is the fault of the 
granting institutions. They just throw money at it and the plans are often not well conceived. I would like to see some sort of standardization if you're going to grant money for hardware for a laboratory, do it this way: disperse enough money for a small number of machines that go onto the desks of targeted faculty, disperse some more money for training of that faculty and training for about an eight-month to year-long period. At the end of that period, when the faculty have been trained and have developed some materials and have investigated some off-the-shelf materials, then come back with some additional funds to open up a limited lab and then run pilots with limited numbers of courses and then still a year later disperse the rest of the funds to install the rest of the lab.

Read: That was the one single reason that labs got the bad name they did and their failure in the '60s was the granting institutions would throw money at hardware but not provide for the ongoing support and all the rest of it. The same thing will happen with these labs if we don't insist up front that we have ongoing support costs for them.

Trish: That, and also really addressing the question of what you want to do in the lab in the first place. Contrary to the idea of "build it and they will come." We learned that really does not work.

Chris: I remember seeing a guideline very recently that said if you're going to buy hardware, for every dollar of hardware, you need a dollar of training, a dollar for software. So you need \$3, so think 30\% hardware and that's simple. Whether that's even enough for training and software is really another question.

Trish: Did you have another question?

Audience Question: First, you're talking about the sort of withering away of the language lab facilities. One of the things I am hearing as a sort of practical matter are sort of non-pedagogical considerations. On the one hand, space crunches in institutions, and on the other hand, especially among the more urban institutions, a reluctance of perhaps students and faculty to come work at these places. So distance learning becomes more of an appealing thing. I'd like you to respond to those ideas. Secondly, as you were talking, Chris, about these three- and four-year cycles and getting people accustomed to this idea, I suddenly remembered that sometimes when I show up at my boss's office, I can see the little cartoon character of the dollar bill with the wings. That's how he sort of sees me. I was wondering if anybody had any insights here about how you deal with money people about that. How do you educate them? 
Chris: Well, the example I gave of where I was before I came to Carnegie Mellon, I was thick as thieves with the computing people. The way they got around it was in terms of the infrastructure of the university. In other words the university made a commitment. The guy said okay listen you're not buying this equipment, you're leasing it. Every year you pay $x$ dollars for a lease, like leasing a new car. You never own it. At the end of the four years, you just keep leasing. Your lease costs will go up. That's the story. You need to think of it in those terms because if you actually think "you buy, you own, it's mine, good, I don't have to worry about it." It's an illusion. You need to think of it as a line item that is there every year, even three years is a disservice. Break down that threeyear period, and say it's going to cost you $x$ dollars per year. How much is it costing you for administrative computing? Why should it cost you less for language computing than what it's costing for administrative computing? They've done the math for administrative computing, you see. That's an accepted part of the infrastructure. You have to say, okay, this is computing just like the rest of the computing in the university, it's going to cost the same amount, if not more of course, but see if you can get to the same amount.

Trish: I wanted to say something, actually, about what does this mean about language labs that don't exist as places anymore either because students feel uncomfortable coming in to work there or because space is a problem. I'm worried about that because I think that we have some evidence that having a place for students to work together is important, that it enables students to do things that they find difficult to do otherwise. Studies have shown that students really, when they think back on their experiences as undergraduates, what they remember are those joint experiences with other people. I think that one of the reasons that language labs were not particularly favorably perceived by students is they were isolating. I mean, it was a place, but it was a place where you went and sat in a booth separate from other people. At Michigan we're working on ways where we can make our facility invite students in, make them feel comfortable, make them feel part of the community. What we have to avoid, though, I think, is making it a place where they have to come there, where it's the only place where they can do certain kinds of things, because then they're trapped. What I'd like to do is make it possible for students to do the work that they need to do in a variety of surroundings, but to make the language lab a place where they want to come, where they get something from that experience there physically that they don't get elsewhere. 
Read: To go back to her question, along with what you're basically saying, let me say that as much as you spend money on equipment you also need to consider things like carpeting and the plants and the comfortable seating and the kinds of things that make it an inviting place to come. If it is an institutional type of place they won't come.

Ruth: Well, actually Read just said what I was about to say. I actually used a large portion of my grant money to improve the surroundings. MIT was willing only to build walls, so I used a lot of grant money to buy nice furniture, to put up nice panels, and I really can't say enough about the different feel of this facility as opposed to other places. Students really do come there because it's a nice place to study. We have a couple of booths that might not have equipment on them, they'll just go and study there like it's a library, and I think it's a very different environment from what we used to offer them.

Audience Comment: One thing I heard all afternoon is that Conclusion this is a changing role not only of the language lab director but the language lab itself. So what we're doing is redefining what we're going to do in the future. The position will still be there.

Trisha Dvorak is the Director of the Language Resource Center at the University of Michigan and the immediate past president of IALL.

Brigitte Charlotteaux is the Director of the Language Lab at George Washington University.

Read Gilgen is the Director of Learning Support Services at the University of Wisconsin-Madison and Acting Editor-in-Chief of the IALL Journal.

David Herren is a Special Assistant to the Vice President of The Language Schools at Middlebury College.

Chris Jones is the Director of the Language Learning Resource Center at Carnegie Mellon University.

Ruth Trometer is the Director of the Language Learning Resource Center at Massachusetts Institute of Technology. 


\section{"Every language laboratory should have at least one copy!"}

A la rencontre de Philippe Gilberte Furstenberg, creator The MIT Athena Language Learning Project

Meet Philippe. He's a young French journalist whose luck has just run out. Over coffee, he asks for your help. After all, how can he find a new apartment in Paris all by himself? You accept, but you'll need some help, too: interacting with native speakers,

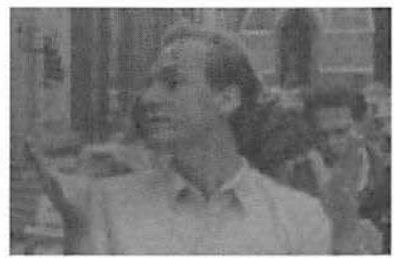
using French phones and answering machines, reading les petites annonces, understanding maps of Paris, and much more. This is the world your French students enter when they turn on their computers and set out $A$ la rencontre de Philippe.
The Philippe program includes:

- interactive videodisc and software for the Macintosh ${ }^{\text {m }}$

- teacher's guide

- student workbook (available separately)

\section{French in Action- The Capretz Method} Now in its second edition!

"The best method ever devised for teaching French." -Alan Astro, Trinity University

Interested in talking with other teachers? Join FIA-L and PHILIP-L, our discussion lists for French teachers on the Internet.

\section{Yale University Press}

Phone: 800-987-7323 • Fax: 203-432-2394

Email: yupmkt@yalevm.cis.yale.edu 